Ágnes Zsila*, Róbert Urbán, Gábor Orosz and Zsolt Demetrovics

\title{
The association of animated sitcom viewing with humor styles and humor types
}

https://doi.org/10.1515/humor-2020-0055

Received November 25, 2019; accepted August 27, 2020;

published online February 9, 2021

\begin{abstract}
Recently, animated sitcoms such as Family Guy and American Dad have generated considerable interest internationally. This genre is known for its portrayal of controversial political and social issues combined with strategies of malicious humor, exaggeration, and stereotyping. This study addresses the question of whether humor styles and humor types predict viewer interest in animated sitcoms. A total of 1,052 Hungarian adults ( $41.6 \%$ male, $M_{\mathrm{age}}=24.7$ years, $\mathrm{SD}=7.2$ ) participated in an online survey focusing on animated sitcom viewing habits and the use of humor. It was found that males and younger individuals were more likely to watch animated sitcoms regularly than females and older individuals. As a result of multiple regressions, it was also found that individuals with high levels of selfenhancing and aggressive humor, and low levels of self-defeating humor were more likely to view animated sitcoms. Regarding humor types, individuals with low levels of all humor styles were less likely to watch animated sitcoms regularly. These findings can possibly contribute to a more nuanced understanding of media selection preferences in the level of individual differences.
\end{abstract}

Keywords: animated sitcom; humor styles; humor types; media preferences; media selection

\section{Introduction}

Animated situation comedies (generally known as animated sitcoms) have been popular since the first release of the successful prime time animation, The

*Corresponding author: Ágnes Zsila, Institute of Psychology, Pázmány Péter Catholic University, Budapest, Hungary, E-mail: zsilagnes@gmail.com

Róbert Urbán and Zsolt Demetrovics, Institute of Psychology, ELTE Eötvös Loránd University, Budapest, Hungary

Gábor Orosz, Unité de Recherche Pluridisciplinaire Sport Santé Société, Laboratoire Sherpas, Université d’Artois, Liévin, France

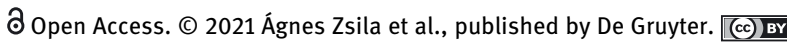
under the Creative Commons Attribution 4.0 International License. 
Flintstones (produced by Hanna-Barbera Productions, Inc., in 1960) (Wells 2003). Although The Flintstones was not targeted solely at children, the content has remained family-friendly over the years, while animated sitcoms created since the 1980s (e.g., The Simpsons, South Park, Family Guy) have been primarily targeted at an adult audience (Turner 2004). The appreciation and enthusiasm of young American viewers for animated sitcoms are clearly reflected in the viewer statistics. According to recent reports, popular animated sitcoms such as The Simpsons, Family Guy, and The Cleveland Show attracted millions of American viewers between 18 and 49 years of age in 2011 (Kenneally 2011). In 2019, Family Guy still drew 2-3 million viewers (tvseriesfinale.com 2019), while South Park attracted 1.4 million young adult viewers (thewrap.com 2019).

The growing popularity of animated sitcoms has opened an avenue to the expansion of the US market, resulting in that the genre became part of the Western popular culture after its introduction to an international audience (Dhaenens and Van Bauwel 2012; Larson 2003). ${ }^{1}$ Despite this widespread interest in animated sitcoms, studies investigating viewers' characteristics are scarce. This study endeavors to address and seek answer to the question of whether there are any differences between animated sitcom viewers and non-viewers in the use of humor. The exploration of differences can contribute to a more nuanced understanding of media content preferences.

Animated sitcoms often dissect controversial or sensitive social and political issues (e.g., gun control, gay marriage) using malicious humor, stereotyping, and exaggeration (Dhaenens andVan Bauwel 2012; Gray 2006; Raymond 2013). Social criticism is also a central element of these cartoons, which can be understood in a US context (Raymond 2013). Juckel et al. (2016) compared non-animated sitcoms (e.g., The Big Bang Theory, Modern Family) with Family Guy in terms of humor categories and techniques, and found that Family Guy presented offensive humor techniques such as parody and absurdity more frequently than non-animated sitcoms, and these are generally derived from situations involving debates about moral and social standards. Juckel, Bellman and Varan (2016) suggested that animated sitcoms portray superiority without moral engagement in a number of cases, and such instances are often accompanied by negative humor.

In the present study we expand upon previous research by investigating the characteristics of people who regularly watch animated sitcoms. Given the

\footnotetext{
1 In Hungary, some popular animated sitcoms (e.g., Family Guy, The Cleveland Show) were introduced to television viewers in the late 2000s, and young viewers between 18 and 49 years of age expressed considerable interest in this genre (origo.hu 2015). Indeed, animated sitcoms such as The Cleveland Show, Family Guy, and Drawn Together were listed among the five most popular Comedy Central shows in the following three years (origo.hu 2013).
} 
offensive nature of animated sitcoms we propose that the age as well as one's humor style (Martin et al., 2003) predict regular viewership.

\subsection{The role of age and gender}

Several studies demonstrated that gender and age play an influential role in media selectivity (e.g., Mares, Oliver and Cantor 2008; Mares and Sun 2010). In relation to situation comedies, some studies reported that younger adults viewed more comedies than older adults (Bartsch 2010; Mares et al. 2008), and younger adults were more likely to view movies to laugh and alleviate boredom (Mares et al.2008). Previous findings also suggest that males use humor more frequently than females (Martin et al. 2003; Svebak et al. 2004), particularly aggressive forms of humor (Martin et al. 2003). In line with this result, males showed a preference for dark comedy genres in the study by Greenwood (2010). Furthermore, males exhibited more positive attitudes towards satire comedy than females (Schwarz et al. 2015). Based on these findings, we hypothesize that males and younger adults are more likely to regularly watch animated sitcoms than females and older adults.

\subsection{The role of humor styles and humor types}

Sarcasm and malicious humor are central elements of animated sitcoms (Dhaenens and Van Bauwel 2012; Raymond 2013). Therefore, animated sitcom viewers may have similar humor styles that would explain their preference for such media content. According to Martin et al. (2003), humor styles reflect individual differences in the use of humor that are represented by four major categories: affiliative, selfenhancing, aggressive, and self-defeating humor styles. Individuals expressing affiliative humor tend to tell jokes in an attempt to amuse others, and hence, improve interpersonal relationships. Those with an increased use of self-enhancing humor have a humorous outlook on life, even in stressful situations. By contrast, the use of aggressive humor involves teasing, sarcasm, and ridicule that are deleterious to social relationships. Finally, self-defeating humor reflects attempts of selfdisparagement performed to amuse others (Martin et al. 2003). According to previous studies, affiliative and self-enhancing humor are benign, positive humor styles, while aggressive and self-defeating humor are deleterious humor styles (Dyck and Holtzman 2013; Martin et al. 2003).

According to Galloway (2010), individuals can be categorized into four major clusters (i.e., humor types) based on their humor style patterns. The first cluster 
consisted of individuals with an increased use of all forms of humor, while the second cluster comprised individuals with a decreased use of all forms of humor. The third cluster involved individuals with a great tendency of using positive humor styles over negative humor styles. Finally, the fourth cluster included individuals with a high tendency of using negative humor styles over positive humor styles.

Leist and Müller (2013) found three humor types as a result of cluster analysis. The first cluster consisted of 'humor endorsers', who scored above average on all humor styles. The second cluster comprised 'humor deniers', who scored below average on all humor styles. Finally, the third cluster included 'self-enhancers', who scored highly above average on self-enhancing humor, slightly above average on affiliate humor, and below average on aggressive and self-defeating humor styles.

Overall, Leist and Müller (2013) identified two clusters (i.e., humor endorsers and humor deniers) that are identical to the clusters found by Galloway (2010) (i.e., Cluster 1 and Cluster 2), and proposed that the third cluster is largely a replication of Galloway's (2010) who offered a clearer and more complex taxonomy of humor types. For these reasons, the present study constructs the four clusters from the data following the protocol suggested by Galloway (2010) to investigate the association of humor types with animated sitcom viewing habits.

Considering that animated sitcoms use parody and malicious humor (Dhaenens and Van Bauwel 2012; Raymond 2013), and that viewers tend to select media content that corresponds to their self-concept (Stroud 2010), it can be hypothesized that animated sitcom viewers have higher levels of aggressive humor compared to non-viewers. Furthermore, considering that animated sitcoms created large fan communities that facilitated social interactions between individuals with a similar interest (Ott 2003), it can be hypothesized that animated sitcom viewers tend to use affiliative humor more frequently than nonviewers. In line with these assumptions, it can be proposed that individuals with a greater tendency to use all forms of humor are more likely to become attracted to animated sitcoms, while individuals with lower levels of all humor styles are less likely to view animated sitcoms.

Considering that some animated sitcoms differ in their portrayal of humor (e.g., Family Guy uses negative humor such associal criticism and absurdity [Juckel et al. 2016], while The Simpsons uses playful and mild humor in the portrayal of family life [Gray 2005]), humor styles and types of different audiences across popular animated sitcoms may also worth investigating. 


\subsection{Study aims and hypotheses}

The aim of this study was to explore individual differences between animated sitcom viewers and non-viewers in terms of humor styles and humor types in order to gain a more nuanced knowledge of the uses of humor that predict animated sitcom viewing. In a broader context, the exploration of possible differences could contribute to a better understanding of individual differences in media content preferences.

Overall, the following hypotheses were formulated based on the literature:

H1: Males will be more likely to regularly watch animated sitcoms than females.

H2: Younger adults will be more likely to regularly watch animated sitcoms than older adults.

H3: Increased use of affiliative and aggressive humor styles will predict animated sitcom viewing in general, while self-enhancing and self-defeating humor styles will not be predictors of animated sitcom viewing in general.

H4: Individuals scoring above average on all humor styles (Cluster 1, according to Galloway [2010]) will be more likely to become animated sitcom viewers in general, while individuals who score below average on all humor styles (Cluster 2, according to Galloway [2010]) will be less likely to become animated sitcom viewers in general.

\section{Method}

\subsection{Participants and procedure}

A total of 2,383 participants ( $46.12 \%$ male, $M_{\text {age }}=24.4$ years, $\mathrm{SD}=7.2$ ) started to complete an online questionnaire focusing on animated sitcom viewing habits. Members of four popular Hungarian online communities dedicated to cartoons were invited to complete the questionnaire. All four groups comprised at least 2,000 members on Facebook. These groups were selected based upon two major aspects: the thematic content (i.e., cartoons) and the number of members (more than 2,000 members). Participation in the survey was voluntary and anonymous. Informed consent was obtained from all participants. This study was carried out 
with the approval of the Institutional Review Board of the research team's university and was performed in compliance with the Declaration of Helsinki.

Preceding the data analysis, responses with severe incompleteness (i.e., study-relevant questions were not answered and less than $30 \%$ of the survey was completed) were excluded $(n=1,221)$ alongside with responses provided by underage individuals $(n=110)$. Therefore, the final sample comprised 1,052 adult participants ( $41.6 \%$ male, $M_{\text {age }}=24.7$ years, $\mathrm{SD}=7.2$ ) between 18 and 66 years of age. More than half of the participants obtained a secondary school certification (59.2\%), whereas $25.8 \%$ had at least college degree, and $15.0 \%$ received only primary school education. One-third of the participants reported being a student (33.9\%), while another one-third worked (32.6\%), and 27.4\% studied and worked at the time of the data collection. Only a small minority of participants neither studied, nor worked (6.1\%).

\subsection{Measures}

Data regarding demographic characteristics (i.e., gender, age, educational level, current studies or work experience) were gathered. Furthermore, humor styles and humor types were examined in relation to animated sitcom viewing habits. Item translation of the assessment instruments used in this study was carried out following the protocol by Beaton et al. (2000).

\subsubsection{Animated sitcom viewing habits}

First, participants were asked whether they had viewed any animated sitcoms in the past year. Second, participants who responded positively to this question were asked to indicate how often they had viewed animated sitcoms during the past year $(1=1-5$ times per year, $2=6-12$ times per year, $3=1-4$ times per month, $4=1-2$ times per week, $5=3-5$ times per week, $6=$ daily or almost daily). Third, these participants were also asked to name those animated sitcoms they had viewed in the past year.

\subsubsection{Humor styles}

Participants' humor styles were assessed by the Humor Styles Questionnaire (HSQ; Martin et al. 2003). The 32-item HSQ comprises four subscales: Affiliative humor (e.g. "I enjoy making people laugh.") ( $\alpha=0.79)$, Self-Enhancing humor (e.g., "Even when I'm by myself, I'm often amused by the absurdities of life.") $(\alpha=0.78)$, Aggressive humor (e.g., "If I don't like someone, I often use humor or teasing to put 
them down.") ( $\alpha=0.72$ ), and self-defeating humor (e.g., "I often go overboard in putting myself down when I am making jokes or trying to be funny.”) ( $\alpha=0.69$ ). Each subscale consists of eight items. According to Galloway (2010), affiliative and self-enhancing humor can be considered as positive humor styles, while aggressive and self-defeating humor are negative humor styles. Participants indicated the extent of which the statements were characteristic of them on a seven-point Likert scale ( 1 = 'totally disagree', 7 = 'totally agree').

\subsubsection{Humor types}

Participants were categorized into four clusters based upon some specific humor style patterns described by Galloway (2010). Cluster 1 comprised participants scoring above average on all humor styles assessed by the Humor Styles Questionnaire (HSQ; Martin et al. 2003). Cluster 2 comprised participants scoring below average on all humor styles. Cluster 3 consisted of participants scoring above average on positive humor styles (i.e., affiliative and self-enhancing humor styles) and below average on negative humor styles (i.e., aggressive and self-defeating humor styles). Cluster 4 involved participants scoring below average on positive humor styles (i.e., affiliative and self-enhancing humor styles) and above average on negative humor styles (i.e., aggressive and self-defeating humor styles) according to the mean scores of the present data.

\subsection{Statistical analysis}

Because viewing frequency varies so greatly, we categorized participants into three groups: regular viewers (those who watch animated sitcoms at least 1-2 times per week), casual viewers (those who watch animated sitcoms between 1 and 5 times per year and 4 times per month), and non-viewers (those who have not watched any animated sitcoms in the past year).

Additional data analysis was conducted on viewers of the three most popular animated sitcoms in the present sample (i.e., Family Guy, South Park, and The Simpsons). To explore clear differences in study-relevant variables across these groups, non-overlapping categories were applied. Therefore, group comparisons were explored across viewers who reported viewing only Family Guy $(n=139)$, South Park $(n=34)$, or The Simpsons $(n=22)$.

In the following step, multinomial logistic regressions were conducted in which age and gender were treated as control variables, while humor styles and humor types were added as predictor variables. Animated sitcom viewer groups (i.e., regular viewers and causal viewers) and non-viewers were entered as 
outcome variables in these analyses. According to the suggestion of Galloway (2010), Cluster 1 consisted of 158 participants (15.02\% of the total sample), Cluster 2 comprised 128 participants (12.17\% of the total sample), Cluster 3 involved 83 participants $(7.89 \%$ of the total sample), and Cluster 4 comprised 47 participants (4.47\% of the total sample). Overall, 416 participants could be categorized into one of the Clusters by Galloway (2010) (39.55\% of the total sample). Participants that could not be categorized into either Cluster were excluded from the regression analysis in which humor types were treated as predictors.

\section{Results}

\subsection{Descriptive statistics}

Overall, more than three-quarters of participants $(n=816 ; 77.6 \%)$ reported viewing animated sitcoms in the past year, and only a small proportion of respondents reported not viewing any animated sitcoms $(n=236 ; 22.4 \%)$. These respondents were labeled as 'non-viewers' in the subsequent data analysis. With regard to animated sitcom viewers, $186(22.8 \%)$ participants reported viewing animated sitcoms daily or almost daily in the past year, while $163(20.0 \%)$ viewed animated sitcoms 3-5 times a week, 177 (21.7\%) 1-2 times a week, and 195 (23.9\%) 1-4 times a month. Only a small minority of animated sitcom viewers reported viewing animated sitcoms $6-12$ times a year $(n=55 ; 6.7 \%)$ or $1-5$ times a year $(n=40 ; 4.9 \%)$. According to the classification described above, half of the participants $(n=526$; $50.0 \%)$ were considered being regular animated sitcom viewers, and $290(27.6 \%)$ participants of the total sample were classified as being casual animated sitcom viewers in the present study. Among animated sitcom viewers $(n=816 ; 77.6 \%)$, the three most frequently reported animated sitcoms that had been viewed in the past year were Family Guy ( $n=670 ; 82.1 \%)$, South Park $(n=485 ; 59.4 \%)$, and The Simpsons ( $n=274 ; 33.6 \%)$. However, only a minority of viewers reported viewing solely Family Guy ( $n=139 ; 17.03 \%$ of animated sitcom viewers), South Park ( $n=34$; $4.17 \%$ of animated sitcom viewers), or The Simpsons ( $n=22 ; 2.70 \%$ of animated sitcom viewers).

\subsection{Investigating differences across viewers of the three most popular animated sitcoms}

It was examined whether there are any differences between viewers of the three most popular animations in the present study. Therefore, differences across 
viewers of Family Guy ( $n=139 ; 17.03 \%)$, South Park $(n=34 ; 4.17 \%)$, and The Simpsons ( $n=22 ; 2.70 \%)$ were investigated (see Table 1$)$.

The one-way ANOVA indicated significant difference in age between viewers of Family Guy and South Park $\left(F_{(2,192)}=5.04, p=0.007\right)$. The Tukey's honestly significant difference post-hoc test revealed that viewers of Family Guy were younger $(M=23.61, \mathrm{SD}=4.64)$ than viewers of South Park $(M=27.15, \mathrm{SD}=9.73$, $p=0.005$, Partial eta $\left.{ }^{2}=0.05\right)$. However, no significant difference was found in humor styles $\left(F_{(2,192)}=0.35, p=0.71\right.$ for affiliative humor; $F_{(2,192)}=1.30, p=0.28$ for self-enhancing humor; $F_{(2,192)}=1.60, p=0.20$ for aggressive humor, and $F_{(2 \text {, }}$ ${ }_{192)}=0.58, p=0.56$ for self-defeating humor). Gender and humor types could not be explored across viewers of Family Guy, South Park, and The Simpsons due to the limited number of participants in several specific subgroups (e.g., the number of daily viewers of South Park was only 1 in the present sample).

Table 1: Group comparisons across viewers of Family Guy, South Park, and The Simpsons in major demographics, humor styles and humor types.

\begin{tabular}{|c|c|c|c|c|c|}
\hline & $\begin{array}{r}\text { Total } \\
(n=195)\end{array}$ & $\begin{array}{r}\text { Viewers of } \\
\text { Family Guy } \\
(n=139)\end{array}$ & $\begin{array}{r}\text { Viewers of } \\
\text { South Park } \\
\quad(n=34)\end{array}$ & $\begin{array}{r}\text { Viewers of } \\
\text { The Simpsons } \\
(n=22)\end{array}$ & $x^{2} / F$ \\
\hline \multicolumn{6}{|c|}{ Demographic characteristics } \\
\hline Gender (male), $n$ (\%) & $73(37.44 \%)$ & $58(41.73 \%)$ & $12(35.29 \%)$ & $3(13.64 \%)$ & NA \\
\hline Age (years), mean (SD) & $24.26(5.97)$ & $23.61(4.64)$ & $27.15(9.73)$ & $23.91(4.78)$ & 5.04 \\
\hline \multicolumn{6}{|l|}{ Animated sitcom viewing } \\
\hline Regular viewers, $n$ (\%) & $98(50.26 \%)$ & $80(57.55 \%)$ & $11(32.35 \%)$ & 7 (31.82\%) & NA \\
\hline Casual viewers, $n$ (\%) & $97(49.74 \%)$ & $59(42.45 \%)$ & $23(67.65 \%)$ & $15(68.18 \%)$ & \\
\hline \multicolumn{6}{|l|}{ Humor styles (range: $1-7$ ) } \\
\hline $\begin{array}{l}\text { Affiliative humor, mean } \\
\text { (SD) }\end{array}$ & $5.67(1.09)$ & $5.69(1.09)$ & $5.70(1.01)$ & $5.49(1.25)$ & 0.35 \\
\hline $\begin{array}{l}\text { Self-enhancing humor, } \\
\text { mean (SD) }\end{array}$ & $4.91(1.13)$ & $4.89(1.14)$ & $5.16(0.98)$ & $4.69(1.27)$ & 1.30 \\
\hline $\begin{array}{l}\text { Aggressive humor, } \\
\text { mean (SD) }\end{array}$ & $3.96(1.07)$ & $4.01(1.05)$ & $4.00(0.96)$ & $3.58(1.29)$ & 1.60 \\
\hline $\begin{array}{l}\text { Self-defeating humor, } \\
\text { mean (SD) }\end{array}$ & $4.11(1.01)$ & $4.06(0.99)$ & $4.27(0.98)$ & $4.11(1.18)$ & 0.58 \\
\hline \multicolumn{6}{|l|}{ Humor types } \\
\hline Cluster $1, n(\%)$ & $40(20.51 \%)$ & $31(77.50 \%)$ & $6(15.00 \%)$ & $3(7.50 \%)$ & NA \\
\hline Cluster 2, $n$ (\%) & $20(10.26 \%)$ & $13(65.00 \%)$ & $3(15.00 \%)$ & $4(20.00 \%)$ & \\
\hline Cluster 3, $n(\%)$ & $13(6.67 \%)$ & $7(53.85 \%)$ & $4(30.77 \%)$ & $2(15.38 \%)$ & \\
\hline Cluster 4, $n(\%)$ & $5(2.62 \%)$ & $2(40.00 \%)$ & $2(40.00 \%)$ & $1(20.00 \%)$ & \\
\hline
\end{tabular}

The boldfaced value represents significant difference between viewers of Family Guy and South Park in age at $p=0.007$. When investigating possible differences across viewer groups in terms of gender and humor types, chi-square tests could not be conducted due to the limited sample size. For age and humor styles, one-way ANOVAs were conducted. Participants who could not be categorized into either Cluster by Galloway (2010) ( $n=117 ; 60 \%$ of the sample of viewers of the most popular animated sitcoms in the present sample) were excluded from the group comparison that was based upon humor types. 


\subsection{Investigating demographic differences across animated sitcom viewing groups}

In the first step, $\mathrm{a} \chi^{2}$ test and a one-way ANOVA with post hoc tests were conducted for group comparisons.

A chi-square test of independence revealed a significant relationship between gender and the frequency of viewing animated sitcoms (regular, casual, non-viewer), $\chi^{2}(2)=36.68, p<0.001$. In more detail, regular viewers were comprised of more men ( $n=265,60.50 \%)$ than women $(n=261,42.51 \%)$. In contrast, casual viewers more evenly comprised of men $(n=106,24.20 \%)$ than women $(n=184,29.97 \%)$. Additionally, the proportion of women $(n=169,27.52 \%)$ in non-viewers was higher than the proportion of men $(n=67,15.30 \%)$. Therefore, Hypothesis 1 was supported.

In addition, a one way analysis of variance (ANOVA) was performed on participants' age with the frequency of viewing animated sitcoms (regular, casual, non-viewer) serving as a between-subjects variable. Supporting Hypothesis 2, the effect of viewing sitcoms was significant, $F_{(2,1049)}=26.08, p<0.001$, Partial eta $^{2}=0.05$. A Tukey's honestly significant difference post-hoc test revealed that the age of regular viewers $(M=23.92, \mathrm{SD}=5.41)$ was not significantly different from that of casual viewers $(M=23.89, \mathrm{SD}=5.94, p=1.00)$. However, both regular and casual viewers were significantly younger than non-viewers $(M=27.66, \mathrm{SD}=10.56$, $p$ 's were $<0.001$, respectively).

\subsection{Investigating the associations of humor styles and humor types across viewer groups}

Provided that viewer groups differed significantly in terms of gender and age according to the preceding group comparisons, in the second step, multinomial logistic regressions were performed to investigate the association of animated sitcom viewing habits with humor styles and humor types while controlling for gender and age. First, the associations of humor styles were examined in relation to animated sitcom viewing (see Table 2).

According to Hypothesis 3, higher levels of affiliative and aggressive humor styles will predict animated sitcom viewing in general, while self-enhancing and self-defeating humor styles will not be predictors of animated sitcom viewing. However, affiliative humor was not a predictor of regular $(B=0.15, \mathrm{SE}=0.09$, $p=0.09)$ or casual $(B=-0.02, \mathrm{SE}=0.10, p=0.82)$ animated sitcom viewing. In contrast, high levels of aggressive humor predicted both regular $(B=0.30$, $\mathrm{SE}=0.08, p<0.001)$ and casual $(B=0.25, \mathrm{SE}=0.09, p=0.006)$ animated sitcom 
Table 2: Multinomial logistic regression model using humor styles as predictors of regular and casual animated sitcom viewing.

\begin{tabular}{|c|c|c|c|}
\hline & $\begin{array}{r}\text { Casual viewers versus } \\
\text { non-viewers } \\
\text { OR [95\% C.I.] }\end{array}$ & $\begin{array}{r}\text { Regular viewers versus } \\
\text { non-viewers } \\
\text { OR [95\% C.I.] }\end{array}$ & $\begin{array}{r}\text { Regular viewers versus } \\
\text { casual viewers } \\
\text { OR [95\% C.I.] }\end{array}$ \\
\hline \multicolumn{4}{|c|}{ Demographic characteristics } \\
\hline Gender: Male & $1.35[0.92-1.98]$ & $2.34[1.65-3.32]$ & $1.74[1.29-2.35]$ \\
\hline Age & $0.94[0.91-0.96]$ & $0.94[0.92-0.96]$ & $1.00[0.98-1.03]$ \\
\hline \multicolumn{4}{|l|}{ Humor styles } \\
\hline Affiliative humor & $0.98[0.81-1.18]$ & $1.16[0.98-1.39]$ & 1.19 [1.02-1.39] \\
\hline Self-enhancing humor & $1.22[1.02-1.46]$ & $1.27[1.08-1.50]$ & $1.05[0.90-1.22]$ \\
\hline Aggressive humor & $1.28[1.07-1.53]$ & $1.35[1.15-1.59]$ & $1.06[0.92-1.22]$ \\
\hline Self-defeating humor & $0.81[0.67-0.97]$ & $0.78[0.66-0.93]$ & $0.97[0.83-1.12]$ \\
\hline
\end{tabular}

Boldfaced coefficients are significant at least at $p<0.05$.

viewing. In addition, high levels of self-enhancing humor predicted both regular $(B=0.24, \mathrm{SE}=0.09, p=0.004)$ and casual $(B=0.20, \mathrm{SE}=0.09, p=0.03)$ animated sitcom viewing, while decreased use of self-defeating humor also predicted regular $(B=-0.24, \mathrm{SE}=0.09, p=0.005)$ and casual $(B=-0.21, \mathrm{SE}=0.09, p=0.03)$ animated sitcom viewing. Therefore, Hypothesis 3 was not supported.

On the basis of Hypothesis 4, it was proposed that individuals who score above average on all humor styles (Cluster 1) will be more likely to view animated sitcoms in general, while individuals who score below average on all humor styles (Cluster 2) will be less likely to watch animated sitcoms. According to the multinomial regression (see Table 3), only regular animated sitcom viewers were less likely to be

Table 3: Multinomial logistic regression model using humor types as predictors of regular and casual animated sitcom viewing.

\begin{tabular}{lrrr}
\hline & $\begin{array}{r}\text { Casual viewers versus } \\
\text { non-viewers } \\
\text { OR [95\% Cl] }\end{array}$ & $\begin{array}{r}\text { Regular viewers versus } \\
\text { non-viewers } \\
\text { OR [95\% Cl] }\end{array}$ & $\begin{array}{r}\text { Regular viewers versus } \\
\text { casual viewers } \\
\text { OR [95\% CI] }\end{array}$ \\
\hline $\begin{array}{l}\text { Demographic characteristics } \\
\text { Gender: Male }\end{array}$ & $1.39[0.95-2.04]$ & $\mathbf{2 . 4 1 [ 1 . 7 1 - 3 . 4 0 ]}$ & $\mathbf{1 . 7 4 [ 1 . 2 9 - 2 . 3 4 ]}$ \\
Age & $\mathbf{0 . 9 4 [ 0 . 9 2 - 0 . 9 6 ]}$ & $\mathbf{0 . 9 4}[\mathbf{0 . 9 2 - 0 . 9 6 ]}$ & $1.00[0.98-1.03]$ \\
Humor types & & & \\
Cluster 1 & $1.67[0.96-2.91]$ & $1.53[0.92-2.56]$ & $0.92[0.61-1.37]$ \\
Cluster 2 & $0.83[0.51-1.35]$ & $\mathbf{0 . 4 6}[\mathbf{0 . 2 9 - 0 . 7 5 ]}$ & $\mathbf{0 . 5 6 [ 0 . 3 5 - 0 . 9 0 ]}$ \\
Cluster 3 & $1.47[0.75-2.87]$ & $1.31[0.71-2.44]$ & $0.90[0.52-1.55]$ \\
Cluster 4 & $1.09[0.43-2.74]$ & $0.99[0.43-2.29]$ & $0.91[0.45-1.83]$ \\
\hline
\end{tabular}

Boldfaced coefficients are significant at least at $p<0.05$. Clusters for humor types were created following the suggestion by Galloway (2010). 
characterized by generally low levels of all humor styles $(B=-0.77, \mathrm{SE}=0.24$, $p=0.002$ ) compared to non-viewers. Therefore, Hypothesis 4 was not supported.

\section{Discussion}

This study investigated individual differences between animated sitcom viewers and non-viewers to increase knowledge of what forms of humor can predict engagement in viewing animated sitcoms. It was found that age alongside aggressive and self-enhancing humor styles predicted general animated sitcom viewing (i.e., both casual and regular viewing), suggesting that younger adults and individuals with an increased use of aggressive and self-enhancing humor are more likely to become attracted to animated sitcoms than older adults and those who use these forms of humor less frequently. Furthermore, gender and relatively low levels of all humor styles were also associated with animated sitcom viewing: women and those with a less frequent use of humor are less likely to become regular animated sitcom viewers.

Preceding the data analysis, one research question was formulated: are there any differences between viewers of the three most popular animations in the present study? Results indicated no difference between viewers of Family Guy, South Park, and The Simpsons in terms of humor styles. The lack of differences could possibly be accounted for the limited sample size. Indeed, it is possible that more varied subsamples of Family Guy, South Park, and The Simpsons viewers in terms of gender, age and other personal characteristics could have served as a basis of more robust group comparisons. However, it is also possible that viewers with different preferences for specific animated sitcoms share a common preference for certain forms of humor which are basic features of this genre.

When investigating individual differences between animated sitcom viewers and non-viewers, four hypotheses were tested. Supporting the first hypothesis, it was found that the proportion of males was higher among regular animated sitcom viewers. However, the proportion of females was higher among casual viewers and non-viewers. These results may suggest that both genders can find amusement in animated sitcoms, but males may be more prone to become dedicated viewers of animated sitcoms. This result is in line with the findings of Greenwood (2010), who found that males had a general preference for negative humor.

Supporting the second hypothesis, younger adults were more likely to become animated sitcom viewers than older adults. This result corresponds with previous findings suggesting that younger individuals may be more prone to become attracted to sitcoms (Bartsch 2010; Mares et al. 2008). 
With regard to humor styles, the third hypothesis proposed that affiliative and aggressive humor styles will predict animated sitcom viewing in general, while self-enhancing and self-defeating humor styles will not predict animated sitcom viewing. According to the present findings, affiliative humor did not predict animated sitcom viewing in general but only regular viewing when compared to casual viewing. In contrast, aggressive humor predicted animated sitcom viewing in general (i.e., casual and regular viewing). An unexpected result was that selfenhancing humor style also predicted animated sitcom viewing. This result suggests that individuals with an increased use self-enhancing humor are more likely to become attracted to this genre. Provided that animated sitcoms portray situations that reflect the incongruities of life, it is possible that the exposure to such media content facilitate viewers' ability to maintain their positive outlook on life even in stressful situations. Considering that the appreciation of sick humor was associated with the use of humor as a coping strategy in the study by Saroglou and Anciaux (2004), it is also possible that some individuals use self-enhancing humor, and hence, seek congruent media content that portrays the absurdities of life in a humorous way in an attempt to increase their psychological well-being. Alternatively, it is also possible that the appreciation of some humor styles, represented by animated sitcoms, is not adapted into real circumstances by the viewer. Indeed, a considerable proportion of viewers watch television shows to escape from reality (Greenwood 2008; Rubin 1983). They may seek the opportunity to become involved in an experience (e.g., exhibiting offensive forms of humor) that cannot be expressed in real-life circumstances without real, potentially negative consequences. Therefore, the appreciation of some forms of humor onscreen may not represent the humor styles used personally by the viewer. Finally, low level of self-defeating humor was identified as a predictor of animated sitcom viewing. A possible explanation could be that individuals with an attraction towards negative humor onscreen may wish to avoid being an object of ridicule after seeing instances of such incidents in their favorite animated sitcoms. Using less self-defeating humor may be protective for them to avoid such situations and maintain their self-esteem.

With regard to humor types, the fourth hypothesis postulated that individuals scoring above average on all humor styles (i.e., Cluster 1, according to Galloway [2010]) are more likely to become animated sitcom viewers, while those with lower levels of all humor styles (i.e., Cluster 2, according to Galloway [2010]) are less likely to become animated sitcom viewers. In partial support of this hypothesis, it was found that only regular animated sitcom viewers were less likely to be characterized by low levels of humor when comparing this group with casual viewers and non-viewers. Humor is a central element of animated shows (Dhaenens and Van Bauwel 2012; Raymond 2013), hence it may not be surprising that individuals 
with a generally low tendency to use many forms of humor are less likely to become attracted to this genre.

The present study is not without its limitations. First, the sample used in this study is not representative of animated sitcom viewers and non-viewers, which limits the generalizability of the results. Future research should investigate possible differences between viewers and non-viewers of animated sitcoms in cross-cultural research settings to find further empirical support for the present findings. Second, due to the cross-sectional research design, it is impossible to determine the directionality of associations. The present study was not designed to contribute to the debate on the direction of associations between selective media exposure and the use of humor; the purpose of this study was to investigate individual differences between viewer groups in order to draw a clearer picture of the forms of humor that can possibly predict attraction towards animated sitcoms. Longitudinal research is needed to investigate the interplay between media exposure and the use of humor in depth. Future research should also inquire about more specific aspects of audiences such as the media platform for viewing animated sitcoms and the social aspects of viewing (e.g., alone or with friends). Finally, when investigating possible differences in viewers of the three most popular animated sitcoms in the present study, some statistical tests could not be conducted due to the limited sample size. Future studies should investigate possible differences across viewers of some specific animated sitcoms using a larger sample.

Despite the limitations, this study identified some important predictors for animated sitcom viewing. The present findings suggest that younger individuals and those with a higher tendency to use aggressive and self-enhancing humor styles and a lower tendency to use self-defeating humor are more likely to become interested in this genre. In addition, women and those who have generally low levels of humor in all aspects are less likely to become regular animated sitcom viewers. These associations offer an insight into the humor mechanisms of a specific audience of animated sitcoms. The findings can possibly provide with a more nuanced picture of humor preferences of viewers that can help producers create animations that contain some specific forms of humor that are more preferable to viewers and can motivate them to view animated sitcoms more frequently. For instance, the present findings suggest that including frequent hints of self-enhancing humor in the content may be appealing to a broader audience of animated sitcom enthusiasts. Potential viewers can also gain a more nuanced knowledge of various humor styles and types that can be associated with a greater likelihood of dedication towards this genre. For scholars, these results may contribute to a more nuanced understanding of media selection preferences in the level of individual differences. 
Research funding: This work is supported by Hungarian National Research, Development and Innovation Office, Grant no. NKFIH-1157-8/2019-DTKKP126835 and New National Excellence Program of the Ministry for Innovation and Technology from the source of the National Research, Development and Innovation Fund, Grant no. ÚNKP-20-4-II.

Declarations of interest: none.

\section{References}

Bartsch, Anne. 2010. Emotional gratification in media use: Exploring experiential and functional types of entertainment gratification. In Paper presented at the 60th Annual Conference of the International Communication Association. Singapore.

Beaton, Dorcas E, Claire Bombardier, Francis Guillemin \& Marcos Bosi Ferraz. 2000. Guidelines for the process of cross-cultural adaptation of self-report measures. Spine 25(24). 3186-3191.

Dhaenens, Frederik \& Sofie Van Bauwel. 2012. Queer resistances in the adult animated sitcom. Television \& New Media 13(2). 124-138.

Dyck, Kyle T. H. \& Susan Holtzman. 2013. Understanding humor styles and well-being: The importance of social relationships and gender. Personality and Individual Differences 55(1). 53-58.

Galloway, Graeme. 2010. Individual differences in personal humor styles: Identification of prominent patterns and their associates. Personality and Individual Differences 48(5). 563-567.

Gray, Jonathan. 2005. Television teaching: Parody, The Simpsons, and media literacy education. Critical Studies in Media Communication 22(3). 223-238.

Gray, Jonathan. 2006. Watching with the Simpsons: Television, parody, and intertextuality. New York: Routledge.

Greenwood, Dara. 2008. Television as escape from self: Psychological predictors of media involvement. Personality and Individual Differences 44(2). 414-424.

Greenwood, Dara. 2010. Of sad men and dark comedies: Mood and gender effects on entertainment media preferences. Mass Communication \& Society 13(3). 232-249.

Juckel, Jennifer, Steven Bellman \& Duane Varan. 2016. A humor typology to identify humor styles used in sitcoms. Humor 29(4). 583-603.

Kenneally, T. 2011. Ratings: 'Family Guy' grabs top numbers, 'Celebrity Apprentice' declines. The Wrap: Covering Hollywood.

Larson, Allen. 2003. Re-drawing the bottom line. In Carol A. Stabile \& Mark Harrison (eds.), Prime time animation: Television animation and American culture, 55-73. London: Routledge.

Leist, Anja K. \& Daniela Müller. 2013. Humor types show different patterns of self-regulation, self-esteem, and well-being. Journal of Happiness Studies 14(2). 551-569.

Mares, Marie-Louise, Mary Beth Oliver \& Joanne Cantor. 2008. Age differences in adults' emotional motivations for exposure to films. Media Psychology 11(4). 488-511.

Mares, Marie-Louise \& Ye Sun. 2010. The multiple meanings of age for television content preferences. Human Communication Research 36(3). 372-396.

Martin, Rod A, Patricia Puhlik-Doris, Gwen Larsen, Jeanette Gray \& Weir Kelly. 2003. Individual differences in uses of humor and their relation to psychological well-being: Development of the Humor Styles Questionnaire. Journal of Research in Personality 37(1). 48-75. 
origo.hu. 2013. Elfuserált életen nevettek a legtöbbet a Comedy Central nézői [Viewers of Comedy Central laughed most at screwed life]. Available at: https://www.origo.hu/teve/20130624-ahogy-ne-eld-az-eleted-a-magyar-comedy-central.html (accessed 20 October 2019).

origo.hu. 2015. Különös társaságban a Family Guy családfője [The head of Family Guy in a strange company]. Available at: https://www.origo.hu/teve/20150508-kulonos-tarsasagban-afamily-guy-csaladfoje.html (accessed 20 October 2019).

Ott, Brian L. 2003. Oh my God, they digitized Kenny!" Travelt in the South Park cybercommunity. In Carol A Stabile \& Mark Harrison (eds.), Prime time animation. Television animation and American culture, 220-242. New York, NY: Routledge.

Raymond, Chase Wesley. 2013. Gender and sexuality in animated television sitcom interaction. Discourse \& Communication 7(2). 199-220.

Rubin, Alan M. 1983. Television uses and gratifications: The interactions of viewing patterns and motivations. Journal of Broadcasting \& Electronic Media 27(1). 37-51.

Saroglou, Vassilis \& Lydwine Anciaux. 2004. Liking sick humor: Coping styles and religion as predictors. Humor 17(3). 257-278.

Schwarz, Uta, Stefan Hoffmann \& Katharina Hutter. 2015. Do men and women laugh about different types of humor? A comparison of satire, sentimental comedy, and comic wit in print ads. Journal of Current Issues and Research in Advertising 36(1). 70-87.

Stroud, Natalie Jomini. 2010. Polarization and partisan selective exposure. Journal of Communication 60(3). 556-576.

Svebak, Sven, Rod A. Martin \& Jostein Holmen. 2004. The prevalence of sense of humor in a large, unselected county population in Norway: Relations with age, sex, and some health indicators. Humor 17(1/2). 121-134.

thewrap.com. 2019. 'South Park' Ratings Down for Season 23 Premiere - But It's Still the Top Cable Comedy in Young Adults (Exclusive). Available at: https://www.thewrap.com/south-parkseason-23-premiere-ratings-crank-yankers/ (accessed 21 October 2019).

Turner, C. 2004. Planet Simpson: How a cartoon masterpiece defined a generation. Cambridge: Da Capo Press.

tvseriesfinale.com. 2019. Family Guy: Season 16 Ratings. Available at: https://tvseriesfinale.com/ tv-show/family-guy-season-16-ratings/ (accessed 20 October 2019).

Wells, Paul. 2003. Smarter than the average art form" Animation in the television era. In Carol A Stabile \& Mark Harrison (eds.), Prime time animation: Television animation and american culture, 15-32. London: Routledge.

\title{
Bionotes
}

\author{
Ágnes Zsila \\ Institute of Psychology, Pázmány Péter Catholic University, Budapest, Hungary \\ zsilagnes@gmail.com
}

Ágnes Zsila, PhD is a psychologist and senior lecturer working at Pázmány Péter Catholic University. Her research interest encompasses a broad range of popular culture, media and fan studies. 


\section{Róbert Urbán}

Institute of Psychology, ELTE Eötvös Loránd University, Budapest, Hungary

Róbert Urbán, PhD, DSc, a health psychologist working as a professor of psychology at Eötvös Loránd University Faculty of Education and Psychology. His research focuses on health-related behaviors (smoking, e-cigarette, eating behaviors, unhealthy use of alcohol, technology related problem behaviors), psychosocial determinants of health and diseases (psychosocial epidemiology), measurement models, psychometrics.

\section{Gábor Orosz}

Unité de Recherche Pluridisciplinaire Sport Santé Société, Laboratoire Sherpas, Université d'Artois, Liévin, France

Gábor Orosz, PhD is a social psychologist working as a research scientist at the Université d'Artois, Liévin. His research encompasses the intersection of social psychology, individual differences and educational psychology and it includes topics such as online leisure behaviors, competition, cheating, and social psychological interventions in education.

\section{Zsolt Demetrovics}

Institute of Psychology, ELTE Eötvös Loránd University, Budapest, Hungary

Zsolt Demetrovics, DSc, is a Clinical Psychologist and Cultural Anthropologist and has a doctorate in addiction science. He is Professor of Psychology and Director of the Institute of Psychology at the Eötvös Loránd University, Budapest, Hungary. His primary research is focused on the epidemiology and psychological background of legal and illegal substance use and behavioral addictions. 